\title{
OriginaL
}

\section{Effect of pioglitazone on various parameters of insulin resistance including lipoprotein subclass according to particle size by a gel-permeation high-performance liquid chromatography in newly diagnosed patients with type 2 diabetes}

\author{
Koji Nakano $^{1), 3)}$, Goji Hasegawa ${ }^{3)}$, Michiaki Fukui ${ }^{3)}$, Masahiro Yamasaki ${ }^{3)}$, Kiyoshi Ishihara ${ }^{1)}$, Tooru Takashima ${ }^{2)}$, \\ Yoshihiro Kitagawa $^{4)}$, Aya Fujinami ${ }^{5)}$, Mitsuhiro Ohta ${ }^{5}$, Hirokazu Hara ${ }^{6}$, Tetsuo Adachi ${ }^{6}$, Masakazu Ogata ${ }^{7}$, \\ Hiroshi Obayashi ${ }^{7)}$ and Naoto Nakamura ${ }^{3)}$ \\ 1) Department of Internal Medicine, Yamashiro Public Hospital, Kyoto, Japan \\ ${ }^{2)}$ Department of Central Laboratory, Yamashiro Public Hospital, Kyoto, Japan \\ ${ }^{3)}$ Department of Endocrinology and Metabolism, Graduate School of Medical Science, Kyoto Prefectural University of Medicine, \\ Kyoto, Japan \\ 4) Department of Internal Medicine, Osaka General Hospital of West Japan Railway Company, Osaka, Japan \\ ${ }^{5)}$ Department of Medical Biochemistry, Kobe Pharmaceutical University, Kobe, Japan \\ 6) Department of Clinical Pharmaceutics, Gifu Pharmaceutical University, Gifu, Japan \\ ${ }^{7)}$ Department of Molecular Biology, Institute of Bio-Response Informatics, Kyoto, Japan
}

\begin{abstract}
Pioglitazone is an insulin-sensitizing agent that has been reported to have anti-arteriosclerotic effects. The aim of this study was to obtain a better understanding of the mechanism involved in the insulin sensitizing effect of pioglitazone. A total of 50 newly diagnosed patients with type 2 diabetes were enrolled in this study and divided into two groups, 25 of who were treated with $15 \mathrm{mg}$ /day pioglitazone and 25 with $500 \mathrm{mg} /$ day metformin for 12 weeks. Changes in various parameters of insulin resistance including lipoprotein subclass according to particle size determined by high performance liquid chromatography, as well as glucose metabolism, were monitored to determine the relationship between lipoprotein subclass and other insulin resistance parameters. Both pioglitazone and metformin treatment were associated with significant reductions in hyperglycemia, HOMA-IR and HbA1c levels. Pioglitazone treatment, but not metformin treatment resulted in significant reductions in serum large very low-density lipoprotein (VLDL: 44.5-64.0 nm) and increases in serum adiponectin levels (both $<0.001$ ). In the pioglitazone group, the change in large VLDL levels correlated positively with changes in HbAlc $(r=0.468, P=0.0174)$, HOMA-IR $(r=0.593, P=0.0014)$, very small LDL $(r=0.714, P<0.0001)$ and net electronegative charged modified-LDL $(r=0.412, P=0.0399)$, and inversely with changes in adiponectin level $(r=-0.526$, $P=0.0061$ ). The results in this study suggest that the hypoglycemic effect of pioglitazone is achieved mainly through improvement of hepatic insulin resistance, and that pioglitazone may have an antiatherosclerotic effect by decreasing serum atherogenic modified-LDL and by increasing adiponectin.
\end{abstract}

Key words: Hepatic insulin resistance, Pioglitazone, Lipoprotein subclass particle size, Large VLDL, Adiponectin

TYPE 2 DIABETES MELLITUS (T2DM) is generally characterized by a combination of defective pancreatic insulin secretion and insulin resistance [1]. Insulin resistance affects skeletal muscle, adipose tis-

Received Jan. 6, 2010; Accepted Feb. 1, 2010 as K10E-006 Released online in J-STAGE as advance publication Feb. 17, 2010

Correspondence to: Goji Hasegawa, M.D., Ph.D., Department of Endocrinology and Metabolism, Graduate School of Medical Science, Kyoto Prefectural University of Medicine, KawaramachiHirokoji, Kamigyo-ku, Kyoto 602-0841, Japan.

E-mail: goji@koto.kpu-m.ac.jp sue and liver, and is associated with clustering of cardiovascular risk factors. Therefore, current objectives of treatment for T2DM include not only normalization of hyperglycemia, but also reduction of hypertension and correction of dyslipidemia both of which contribute to an increased risk for coronary heart disease [2, 3]. A reduction in insulin resistance may confer beneficial changes in additional components of the insulin resistance syndrome, independent of improvements in glucose metabolism [4]. Therefore, oral antihyperglycemic medication (OAM) therapies that target elevat- 
ed insulin resistance are a rational treatment strategy for also improving cardiovascular risk profile.

Several classes of OAMs are available for the treatment of T2DM and include sulfonylusureas (SU), glitinides, biguanides, $\alpha$-glucosidase inhibitors and thiazolidinediones (TZDs). Pioglitazone, a TZD, is a selective nuclear peroxisome proliferator-activated receptor- $\gamma$ (PPAR- $\gamma$ ) agonist, and has been shown to improve blood glucose and plasma lipoprotein profiles by modulating the transcription of genes that play key roles in carbohydrate and lipid metabolism. There is a large volume of literature that pioglitazone also improves endothelial dysfunction and other inflammatory conditions in the vasculature when given either as monotherapy or in combination with metformin or SU therapy [4-14].

To better understand the mechanism of the insulin sensitizing action of pioglitazone, we compared the effect of pioglitazone and metformin on glucose metabolism and various parameters of insulin resistance including abdominal fat distribution, adipokines, inflammatory factors and lipoprotein subclass according to particle size in newly diagnosed Japanese patients with T2DM. This study was designed to compare the efficacy of standard-dose pioglitazone $(15 \mathrm{mg} /$ day $)$ or metformin (500 mg/day).

\section{Material and Methods}

\section{Patients and research design}

The study was conducted in accordance with the Declaration of Helsinki and the protocol was approved by the regional Ethical Committee of each hospital. All the patients gave their informed consent prior to enrollment in the study. A total of 50 newly diagnosed patients with T2DM (25 men and 25 women; age 54.0 \pm 5.2 years [mean $\pm \mathrm{SD}])$ who were treated with either dietary therapy alone $(n=44)$ or a stable-dose of glimepiride ( 1 or $2 \mathrm{mg} /$ day, $\mathrm{n}=6$ ), were recruited from the outpatient clinics of Yamashiro Public Hospital, Osaka General Hospital of the West Japan Railway Company and Kyoto Prefectural University Hospital. The exclusion criteria were as follows: (i) a serum creatinine concentration $\geq 106 \mu \mathrm{mol} / \mathrm{L}$; (ii) chronic liver disease or a clinical history and/or signs of cardiovascular, cerebrovascular or peripheral arterial disease; (iii) heavy smoking or drinking; and (iv) use of any dietary and/or antioxidant supplements in the 3 months preceding the study. None of the patients had microal- buminuria or diabetic retinopathy or had received other hypoglycemic drugs such as glucosidase inhibitors, biguanides, thiazolidinediones and/or insulin in the 3 months preceding the study.

The study was a randomized, open-labeled, parallel-comparator design of 12 weeks of duration. Twenty-five patients were treated with $15 \mathrm{mg} /$ day pioglitazone (Pio-group) and 25 patients were treated with $500 \mathrm{mg}$ /day metformin (Met-group). The age, sex ratio and duration of diabetes in the two groups are shown in Table 1. In the Pio-group, 6 patients (24\%) were receiving a stable-dose of antihypertensive medication and 4 patients $(16 \%)$ were receiving a low-dose of lipid-lowering medication. In the Metgroup, 5 patients $(20 \%)$ were receiving a stable-dose of antihypertensive medication and 4 patients (16\%) were receiving a low-dose of lipid-lowering medication. No changes were made to these antihypertensive and lipid-lowering therapies during the study. All the patients were asked to adhere to a dietary plan tailored to their energy requirements and metabolic control. The dietary plans were formulated by a registered dietitian and/or a medical doctor using the current Japan Diabetes Society recommendations (JDSR) and were maintained throughout the study.

\section{Biochemical analyses and measurement of abdominal adipose tissue}

Blood samples were obtained in the morning after an overnight fast. Plasma glucose was measured by the glucose oxidase method, $\mathrm{HbAlc}$ by high performance liquid chromatography (HPLC: Arkray Inc., Kyoto, Japan) and serum insulin (immunoreactive insulin: IRI) concentration by an immunoradiometric assay (Insulin-RIAbead II, Abbott, Japan). The homeostasis model assessment index of insulin resistance (HOMAIR) was calculated from fasting insulin and glucose levels by the following equation: HOMA-IR = fasting IRI $(\mathrm{mU} / \mathrm{mL}) \times$ fasting PG $(\mathrm{mg} / \mathrm{dL}) / 405)$. Serum total cholesterol (T-Ch), high-density lipoprotein cholesterol (HDL-Ch), low-density lipoprotein cholesterol (LDL-Ch), free fatty acid (FFA) and triglyceride (TG) were measured by enzymatic methods using a chemical autoanalyzer (Hitachi Co., Tokyo, Japan).

Serum lipoproteins were also analyzed by an gelpermeation HPLC system according to the procedure described by Okazaki et al. [15], while lipoprotein particle size was determined based on individual elution times that corresponded to peaks on the chro- 
Table 1. Baseline clinical profiles and changes in glycemic and lipid parameters and body mass index in each study group

\begin{tabular}{|c|c|c|c|c|}
\hline & \multicolumn{2}{|c|}{ Pioglitazone group $(\mathrm{n}=25)$} & \multicolumn{2}{|c|}{ Metformin group $(n=25)$} \\
\hline & Baseline & After 12 weeks & Baseline & After 12 weeks \\
\hline Age (yrs) & $52.9 \pm 5.3$ & - & $53.2 \pm 5.1$ & - \\
\hline Sex (n; male / female) & $15 / 10$ & - & $15 / 10$ & - \\
\hline Duration of diabetes (months) & $11.6 \pm 3.3$ & - & $11.3 \pm 3.8$ & - \\
\hline Body mass index $\left(\mathrm{kg} / \mathrm{m}^{2}\right)$ & $24.1 \pm 3.1$ & $24.7 \pm 3.0$ & $24.0 \pm 3.3$ & $23.3 \pm 3.1$ \\
\hline Systolic blood pressure $(\mathrm{mmHg})$ & $131 \pm 16$ & $127 \pm 16$ & $130 \pm 17$ & $128 \pm 13$ \\
\hline Diastolic blood pressure $(\mathrm{mmHg})$ & $80 \pm 11$ & $78 \pm 10$ & $81 \pm 9$ & $78 \pm 10$ \\
\hline $\mathrm{HbA} 1 \mathrm{c}(\%)$ & $7.3 \pm 0.7$ & $6.8 \pm 0.6 *$ & $7.2 \pm 0.6$ & $6.8 \pm 0.5 *$ \\
\hline Fasting plasma glucose $(\mathrm{mmol} / \mathrm{L})$ & $7.23 \pm 0.41$ & $6.89 \pm 0.44^{\dagger}$ & $7.21 \pm 0.47$ & $6.85 \pm 0.46^{\dagger}$ \\
\hline Fasting serum insulin $(\mathrm{mU} / \mathrm{L})$ & $8.0 \pm 3.0$ & $7.3 \pm 3.1 *$ & $7.9 \pm 3.6$ & $7.6 \pm 3.2$ \\
\hline HOMA-IR & $2.57 \pm 1.21$ & $2.26 \pm 1.14^{\dagger}$ & $2.58 \pm 1.18$ & $2.34 \pm 1.16 *$ \\
\hline Total cholesterol $(\mathrm{mmol} / \mathrm{L})$ & $5.51 \pm 0.52$ & $5.50 \pm 0.53$ & $5.48 \pm 0.49$ & $5.42 \pm 0.40$ \\
\hline HDL cholesterol $(\mathrm{mmol} / \mathrm{L})$ & $1.36 \pm 0.18$ & $1.39 \pm 0.21$ & $1.36 \pm 0.15$ & $1.38 \pm 0.18$ \\
\hline LDL cholesterol $(\mathrm{mmol} / \mathrm{L})$ & $3.16 \pm 0.88$ & $3.14 \pm 0.93$ & $3.11 \pm 0.91$ & $3.09 \pm 0.99$ \\
\hline Triglyceride $(\mathrm{mmol} / \mathrm{L})$ & $2.10 \pm 0.94$ & $1.89 \pm 1.08$ & $2.05 \pm 1.02$ & $1.99 \pm 0.99$ \\
\hline Free fatty acids $(\mathrm{mEq} / \mathrm{L})$ & $0.70 \pm 0.29$ & $0.60 \pm 0.30$ & $0.67 \pm 0.26$ & $0.62 \pm 0.29$ \\
\hline Electronegative charge-modified LDL $\left(\mathrm{ecd}^{*}\right)$ & $5.4 \pm 3.6$ & $3.5 \pm 2.9 *$ & $5.5 \pm 3.7$ & $3.8 \pm 3.6 *$ \\
\hline
\end{tabular}

Data are the mean \pm SD. $* P<0.05 v s$. baseline. ${ }^{\dagger} P<0.01$ vs. baseline. " electronegative charge density.

matographic pattern of cholesterol fractions. In this study, we defined 3 VLDL, 4 LDL and 5 HDL subclasses according to lipoprotein particle size, expressed as diameter [16].

The net electronegative charge modified-LDL (emLDL) was analyzed using an agarose gel electrophoresis lipoprotein fraction system, according to the manufacturer's instructions (Chol/Trig Combo System $^{\mathrm{TM}}$; Helena Labs, Saitama, Japan). The percentage frequency of emLDL was calculated on a computer from the migration distance (b) of the LDL fraction in the test samples and the migration distance (a) of normal control sera according to the following formula: emLDL density $=[b-a / a] \times 100 \%$.

The serum levels of leptin were measured by a radioimmunoassay (Linco Research Inc., St Charles, MO, USA) and serum levels of extracellular-superoxide dismutase (EC-SOD), resistin and brain-derived neurotrophic factor (BDNF) by enzyme-linked immunosorbent assays (ELISAs), as described in our previous reports [17-19]. ELISA methods were also used to measure the serum levels of adiponectin (Otsuka Pharmaceutical, Tokyo, Japan), Tumor necrosis factor- $\alpha$ (TNF- $\alpha$; R\&D Systems INC., Minneapolis, $\mathrm{MN}, \mathrm{USA}$ ) and high-sensitivity C-reactive protein (hsCRP; Angiopharma, O'Fallon, MO, USA).

The intra-abdominal visceral and subcutaneous fat areas were determined at the umbilical level by a com- puted tomography (CT) scanning technique (TSX012A, X-Vigor, Toshiba Co. Ltd., Tokyo, Japan) using a method described previously [20].

\section{Statistical analysis}

All statistical analyses were performed using Statview version 5.0 (Abacus Concepts, Berkeley, CA, USA), with data expressed as the means \pm SD. Data not distributed normally were logarithmically transformed for analysis. The baseline data of the two groups were compared using Student's unpaired $t$-tests. Within-treatment comparisons of the mean changes in variables from baseline to week 16 were performed using paired $t$-tests and the mean changes in variables between the two groups compared using the analysis of covariance (ANCOVA) test with adjustment for baseline values. The degree of correlation between selected variables was determined by Spearman's correlation analysis. A $P$ value $<0.05$ was considered statistically significant.

\section{Results}

\section{Baseline characteristics}

The baseline clinical characteristics and laboratory data of the patients with T2DM who completed the study are shown in Table 1,2 and 3. All the variables examined were similar in the two groups. 
Table 2. Changes in body fat distribution, adipokines and inflammatory parameters in each study group

\begin{tabular}{lccccc}
\hline & \multicolumn{2}{c}{ Pioglitazone group $(\mathrm{n}=25)$} & & \multicolumn{2}{c}{ Metformin group $(\mathrm{n}=25)$} \\
\cline { 2 - 3 } \cline { 5 - 6 } & Baseline & After 12 weeks & & Baseline & After 12 weeks \\
\hline Visceral fat area $\left(\mathrm{cm}^{2}\right)$ & $106.5 \pm 35.2$ & $97.3 \pm 34.3$ & & $110.2 \pm 30.3$ & $109.1 \pm 26.6$ \\
Subcututaneous fat area $\left(\mathrm{cm}^{2}\right)$ & $127.8 \pm 54.0$ & $135.8 \pm 58.1$ & & $128.4 \pm 43.3$ & $126.5 \pm 36.6$ \\
V / S ratio & $0.92 \pm 0.39$ & $0.80 \pm 0.26 *$ & & $0.95 \pm 0.52$ & $0.93 \pm 0.41$ \\
Adiponectin $(\mu \mathrm{g} / \mathrm{mL})$ & $5.5 \pm 1.5$ & $8.1 \pm 2.2^{\dagger, *}$ & & $5.6 \pm 1.7$ & $6.0 \pm 2.0$ \\
Leptin $(\mathrm{ng} / \mathrm{mL})$ & $3.2 \pm 1.6$ & $3.5 \pm 1.9$ & & $3.1 \pm 2.0$ & $3.3 \pm 1.8$ \\
Resistin $(\mathrm{ng} / \mathrm{mL})$ & $7.7 \pm 3.2$ & $7.3 \pm 4.1$ & & $7.5 \pm 3.5$ & $7.3 \pm 3.7$ \\
Tumor necrosis factor- $\alpha(\mathrm{pg} / \mathrm{mL})$ & $3.2 \pm 0.7$ & $2.7 \pm 1.0 *$ & & $3.1 \pm 0.9$ & $2.9 \pm 1.1$ \\
Brain-derived neurotrophic factor $(\mathrm{ng} / \mathrm{mL})$ & $16.3 \pm 6.1$ & $17.8 \pm 7.7$ & & $15.9 \pm 5.7$ & $16.7 \pm 5.9$ \\
High-sensitivity C-reactive protein $(\mathrm{ng} / \mathrm{mL})$ & $662 \pm 378$ & $648 \pm 404$ & & $654 \pm 359$ & $639 \pm 385$ \\
Extracellular-superoxide dismutase $(\mathrm{ng} / \mathrm{mL})$ & $71.0 \pm 7.5$ & $74.7 \pm 6.9$ & & $71.5 \pm 5.5$ & $73.5 \pm 7.1$ \\
\hline
\end{tabular}

Data are the mean \pm SD. ${ }^{*} P<0.05$ vs. baseline. ${ }^{\dagger} P<0.001$ vs. baseline. ${ }^{\ddagger} P<0.01$ vs. metformin group.

Table 3. Changes in the cholesterol concentration of each lipoprotein subclass, according to particle size in each study group

\begin{tabular}{|c|c|c|c|c|}
\hline & \multicolumn{2}{|c|}{ Pioglitazone group $(\mathrm{n}=25)$} & \multicolumn{2}{|c|}{ Metformin group $(n=25)$} \\
\hline & Baseline & After 12 weeks & Baseline & After 12 weeks \\
\hline \multicolumn{5}{|l|}{ VLDL $(\mathrm{mg} / \mathrm{dL}):$} \\
\hline large $(44.5-64.0 \mathrm{~nm})$ & $5.7 \pm 1.2$ & $4.2 \pm 1.1^{\ddagger / \S}$ & $5.8 \pm 1.2$ & $5.1 \pm 1.4$ \\
\hline medium $(36.8 \mathrm{~nm})$ & $11.1 \pm 2.3$ & $11.4 \pm 2.3$ & $11.5 \pm 3.1$ & $11.1 \pm 2.9$ \\
\hline small $(31.3 \mathrm{~nm})$ & $9.7 \pm 2.2$ & $9.8 \pm 2.3$ & $9.3 \pm 3.0$ & $9.6 \pm 2.7$ \\
\hline \multicolumn{5}{|l|}{$\mathrm{LDL}(\mathrm{mg} / \mathrm{dL})$} \\
\hline large $(28.6 \mathrm{~nm})$ & $28.0 \pm 5.6$ & $28.1 \pm 5.3$ & $27.2 \pm 5.0$ & $26.9 \pm 5.5$ \\
\hline medium $(25.5 \mathrm{~nm})$ & $45.3 \pm 7.4$ & $46.0 \pm 7.5$ & $46.2 \pm 7.4$ & $46.0 \pm 7.1$ \\
\hline small $(23.0 \mathrm{~nm})$ & $35.6 \pm 5.9$ & $35.2 \pm 5.5$ & $35.5 \pm 4.2$ & $35.9 \pm 4.9$ \\
\hline very small $(16.7-20.7 \mathrm{~nm})$ & $18.7 \pm 3.5$ & $16.3 \pm 3.8 \dagger$ & $19.0 \pm 4.2$ & $17.2 \pm 3.8 *$ \\
\hline \multicolumn{5}{|l|}{ HDL (mg/dL) } \\
\hline very large $(13.5-15.0 \mathrm{~nm})$ & $4.5 \pm 1.0$ & $4.8 \pm 0.9$ & $4.3 \pm 1.3$ & $4.4 \pm 0.9$ \\
\hline large $(12.1 \mathrm{~nm})$ & $14.1 \pm 2.1$ & $15.0 \pm 2.5$ & $14.1 \pm 2.2$ & $14.6 \pm 2.9$ \\
\hline medium (10.9 nm) & $16.9 \pm 2.7$ & $17.3 \pm 2.9$ & $16.3 \pm 3.9$ & $16.4 \pm 4.1$ \\
\hline small $(9.8 \mathrm{~nm})$ & $12.0 \pm 2.2$ & $12.1 \pm 2.1$ & $11.9 \pm 2.2$ & $12.0 \pm 2.0$ \\
\hline very small $(7.6-8.8 \mathrm{~nm})$ & $5.2 \pm 1.0$ & $5.4 \pm 1.0$ & $5.3 \pm 1.4$ & $5.4 \pm 1.1$ \\
\hline
\end{tabular}

Data are the mean \pm SD. ${ }^{*} P<0.05 v s$. baseline. ${ }^{\dagger} P<0.01 v s$. baseline. ${ }^{\ddagger} P<0.001$ vs. baseline. ${ }^{\S} P<0.05 v s$. metformin group.

\section{Changes in BMI, indices of glucose control, lipid parameters and blood pressure}

After 12 weeks, BMI was increased in the Piogroup and decreased in the Met-group. However, the differences from baseline values were not statistically significant in either group. Systolic blood pressure (sBP) and diastolic blood pressure (dBP) were decreased in both groups at the end of the study (i.e. after 12 weeks), although this difference from baseline was not statistically significant in either group. There was no significant difference in BMI, sBP or dBP between the two treatment groups at the end of the study.

After 12 weeks, HbAlc decreased significantly compared to baseline levels in both the Pio-group $(-0.5 \%, P<0.05)$ and the Met-group $(-0.4 \%, P<0.05)$.
Similarly, the mean fasting plasma glucose (FPG) levels were decreased significantly from baseline in the Pio-group $(-0.34 \mathrm{mmol} / \mathrm{L}, P<0.01)$ and the Met-group $(-0.36 \mathrm{mmol} / \mathrm{L}, P<0.01)$. In the Pio-group, mean fasting serum insulin (FSI) level was reduced significantly reduced at week 12 by $-0.7 \mathrm{mU} / \mathrm{L}$ from the baseline value of $8.0 \mathrm{mU} / \mathrm{L}(P<0.05)$. The FSI level was also decreased in the Met-group, although the difference from baseline was not statistically significant. After 12 weeks, the mean HOMA-IR level was reduced significantly from baseline in both the Pio-group $(-0.31$, $P<0.01)$ and the Met-group $(-0.24, P<0.05)$. At the end of the study, there were no statistically significant differences in HbA1c, FPG, FSI and HOMA-IR between the two groups. 
There were no statistically significant changes in T-Ch, HDL-Ch, LDL-Ch, TG and FFA in either group. However, both treatment groups had a statistically significant reduction from baseline in emLDL ( $P<0.05$ for both groups). There was no significantly difference in T-Ch, HDL-Ch, LDL-Ch, TG, FFA and emLDL between the two groups at the end of study.

\section{Changes of body fat distribution, adipokines and inflammatory parameters}

In the Pio-group, visceral fat area (VFA) tended to decrease $\left(107 \pm 35\right.$ to $\left.97 \pm 33 \mathrm{~cm}^{2}, P=0.0583\right)$ and subcutaneous fat areas (SFA) tended to increase (128 \pm 54 to $\left.136 \pm 358 \mathrm{~cm}^{2}, P=0.1352\right)$. This resulted in the VFA/SFA ratio decreasing significantly $(0.92 \pm$ 0.39 to $0.80 \pm 0.26, P=0.0391)$. In contrast, VFA, SFA and VFA/SFA ratio did not change in the Met-group. Despite this latter finding, there was no significant difference in VFA, SFA and VFA/SFA ratio between the two groups at the end of the study.

After 12 weeks, serum adiponectin level was increased significantly $(5.5 \pm 1.5$ to $7.9 \pm 2.2, P<0.001)$ in the Pio-group, but remained unchanged in the Metgroup. As a result, at the end of the study, mean serum adiponectin level in the Pio-group was significantly higher than in the Met-group $(8.1 \pm 2.2$ vs. 6.0 $\pm 2.0 \mu \mathrm{g} / \mathrm{mL}, P<0.01)$. Although serum EC-SOD level tended to increase $(71.0 \pm 7.4$ to $74.7 \pm 6.9 \mathrm{ng} / \mathrm{mL}$, $P=0.1137)$ and serum TNF- $\alpha$ level tended to decrease ( $3.2 \pm 0.7$ to $2.8 \pm 1.0 \mathrm{ng} / \mathrm{mL}, P=0.1096)$ in the Piogroup, there were no statistically significant changes in leptin, resistin, BDNF or hsCRP in either group.

\section{Changes of lipoprotein subclasses according to particle size}

The changes in the cholesterol concentration of each lipoprotein subclass determined by particle size are summarized in Table 3. Large VLDL (44.5-64.0 $\mathrm{nm})$ levels were decreased significantly compared with baseline in the Pio-group $(5.7 \pm 1.2$ to $4.2 \pm 1.1$ $\mathrm{mg} / \mathrm{dL}, P<0.001)$. In the Met-group, large VLDL levels tended to decrease compared with baseline, although the difference did not reach statistical significance $(-0.7 \mathrm{mg} / \mathrm{dL}, P=0.093)$. At the end of the study, the mean large VLDL level in the Pio-group was significantly lower than in the Met-group (4.2 \pm 1.1 vs. 5.1 $\pm 1.4 \mathrm{mg} / \mathrm{dL}, P<0.05)$. In the Pio-group, very small LDL levels decreased significantly compared with baseline $(18.7 \pm 3.5$ to $16.3 \pm 3.8 \mathrm{mg} / \mathrm{dL}, P<0.01)$. In the Met-group, very small LDL levels tended to decrease compared with baseline, although the difference did not reach statistical significance $(-1.4 \mathrm{mg} / \mathrm{dL}$, $P=0.089)$. There was no significant difference in very small LDL levels between the two groups at the end of the study. No significant changes from baseline levels were observed in any of the other lipoprotein subclass in either group.

\section{Relationships between the changes in variables in the Pio-group}

In the Pio-group, the change in large VLDL levels showed significant positive correlations with changes in HbA1c ( $r=0.468, P=0.0174$ : Fig.1-A), HOMAIR $(r=0.593, P=0.0014$ : Fig. $1-B)$, very small LDL $(r=0.714, P<0.0001$; Fig. $1-C)$ and emLDL $(r=0.412$, $\mathrm{P}=0.0399$ : Fig. $1-\mathrm{D})$, and a significant inverse correlation with changes in adiponectin $(r=-0.526, P=0.0061$ : Fig.1-F). The change in large VLDL levels also correlated positively with changes in V/S ratio $(r=0.293$, $P=0.1565$ : Fig. 1 -E $)$ and TNF- $\alpha(r=0.321, P=0.1189$ : Fig.1-G, and correlated negatively with changes in EC-SOD ( $r=0.330, P=0.1075$ : Fig. $1-\mathrm{H})$ although these relationships did not reach statistical significance.

\section{Discussion}

The primary aim of this study was to investigate the effects of pioglitazone therapy on lipid metabolism, given that the key component of the insulin resistance is dyslipidemia. The noteworthy finding of this study was that serum levels of both large VLDL ((44.5-64.0 $\mathrm{nm}$ ), corresponding to VLDL1 (Sf 60-400), and very small LDL (7.6-8.8 nm) were reduced significantly by a 12 -week course of standard-dose $(15 \mathrm{mg} /$ day $)$ pioglitazone therapy. However, serum levels of conventional lipids and/or lipoproteins remained unchanged. This finding essentially agrees with the report of Deeg et al. [21] who used proton nuclear magnetic resonance analysis to show pioglitazone treatment, but not rogiglitazone, caused a significant decrease in both large VLDL and small LDL. In addition, we demonstrated that the changes in large VLDL levels associated with pioglitazone therapy correlated positively with changes in HbA1c, HOMA-IR, very small LDL and emLDL, and correlated negatively with change in adiponectin. An increased serum level of large VLDL (VLDL1) is a common characteristic of the dyslipidemia associated with insulin resistance and T2DM 
A

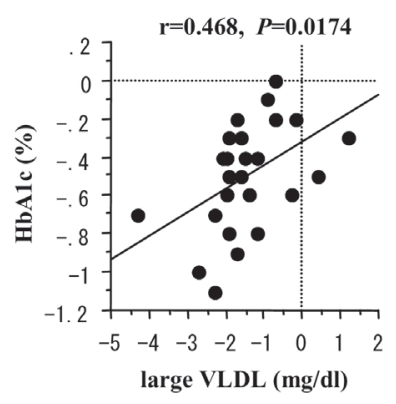

E

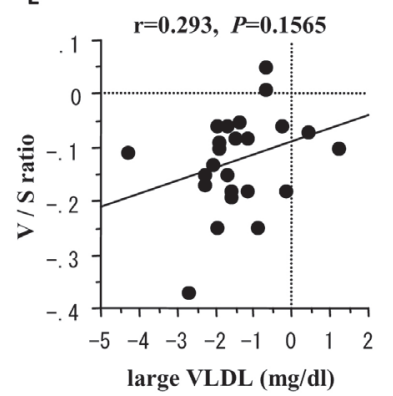

B

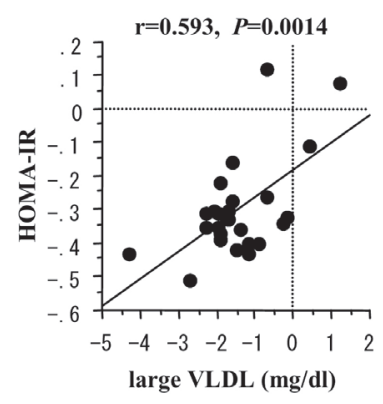

$\mathrm{F}$

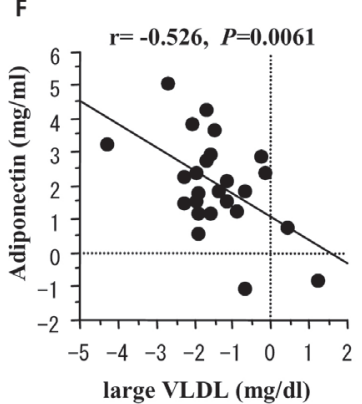

c

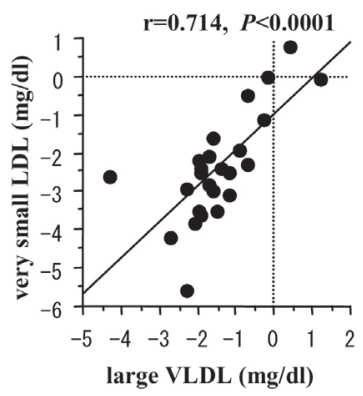

G

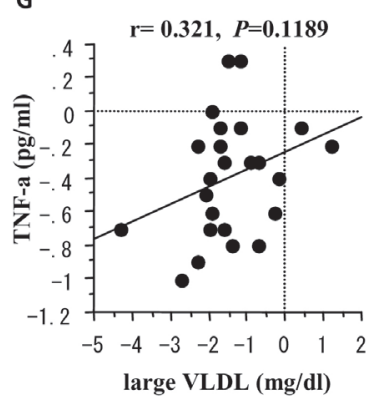

D

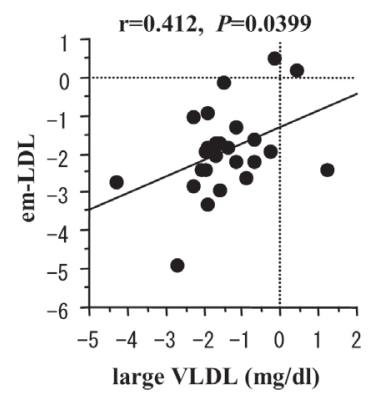

H

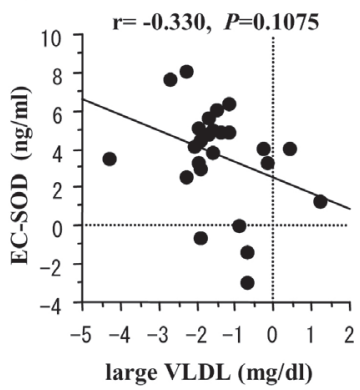

Fig. 1. The correlation between changes in serum large VLDL and (A) HbAlc, (B) HOMA-IR, (C) very small LDL, (D) emLDL, (E) V/S ratio, (F) adiponectin, (G) TNF- $\alpha$, and (H) EC-SOD after 12-week treatment of standard-dose (15 mg/day) pioglitazone.

[22-24]. Griffin and Packard [25, 26] demonstrated that large VLDL1 is a precursor of small dense LDL, and that it is produced preferentially in the liver during development of insulin resistance. Adiels et al. reported that overproduction of large VLDL particles is driven by increased liver fat content [27] and that acute suppression of VLDL1 secretion by insulin is associated with hepatic fat content and insulin resistance [28]. Taken together these previous data and the findings of present study that pioglitazone ameliorates hepatic insulin resistance.

AMP-activated protein kinase (AMPK) is considered as the master switch that regulates glucose and lipid metabolism. It has been reported that both metformin [29] and pioglitazone [30] activate AMPK. Yamauchi et al. also reported that adiponectin activates AMPK, thereby directly regulating glucose and lipid metabolism [31]. In this study, we demonstrated pioglitazone therapy, but not metformin therapy, increased serum adiponectin levels significantly levels and that this change correlated negatively with changes in large VLDL levels. These results therefore suggest that the decrease in serum large VLDL particles caused by pioglitazone therapy was, in part, mediated by an increase in adiponectin synthesis.
In this study, we demonstrated also that the changes in large VLDL levels associated with pioglitazone therapy correlated positively with changes in V/S ratio, TNF- $\alpha$, and correlated negatively with changes in EC-SOD, although these relationships did not reach statistical significance. It is well known that these parameters were associated with systemic vascular insulin resistance.

In summary, the major results in this study are as follows: 1) A 12-week course of standard-dose pioglitazone therapy decreased serum large VLDL, very small LDL, and emLDL; 2) In agreement with numerous previously published results, this therapy was shown to decrease HbA1c, FPG, HOMA-IR and V/ $\mathrm{S}$ ratio and increase serum adiponectin; 3 ) The change we observed in large VLDL correlated positively with changes in HbA1c, HOMA-IR, vary small LDL, emLDL, V/S ratio and TNF- $\alpha$, and correlated negatively with change in adiponectin and EC-SOD. The results of this study suggest that the hypoglycemic effect of pioglitazone is achieved mainly through improvement of hepatic insulin resistance, and that pioglitazone have an antiatherosclerotic effect by decreasing serum atherogenic modified-LDL and increasing adiponectin. 


\section{References}

1. Gerich JE (2003) Contributions of insulin-resistance and insulin-secretory defects to the pathogenesis of type 2 diabetes mellitus. Mayo Clin Proc 78: 447-456.

2. UK Prospective Diabetes Study (UKPDS) Group (1998) Intensive blood-glucose control with sulphonylureas or insulin compared with conventional treatment and risk of complications in patients with type 2 diabetes (UKPDS 33). Lancet 352: 837-853.

3. UK Prospective Diabetes Study (UKPDS) Group (1998) Tight blood pressure control and risk of macrovascular and microvascular complications in type 2 diabetes: UKPDS 38. Br Med J 317: 703-713.

4. Martens FM, Visseren FL, Lemay J, de Koning EJ, Rabelink TJ (2002) Metabolic and additional vascular effects of thiazolidinediones. Drugs 62: 1463-1480.

5. Miyazaki Y, Mahankali A, Matsuda M, Glass L, Mahankali S, Ferrannini E, Cusi K, Mandarino LJ, DeFronzo RA (2001) Improved glycemic control and enhanced insulin sensitivity in type 2 diabetic subjects treated with pioglitazone. Diabetes Care 24: 710-719.

6. Miyazaki Y, Mahankali A, Matsuda M, Mahankali S, Hardies J, Cusi K, Mandarino LJ, DeFronzo RA (2002) Effect of pioglitazone on abdominal fat distribution and insulin sensitivity in type 2 diabetic patients. J Clin Endocrinol Metab 87: 2784-2791.

7. Bajaj M, Suraamornkul S, Pratipanawatr T, Hardies LJ, Pratipanawatr W, Glass L, Cersosimo E, Miyazaki Y, DeFronzo RA (2003) Pioglitazone reduces hepatic fat content and augments splanchnic glucose uptake in patients with type 2 diabetes. Diabetes 52: 1364-1370.

8. Rosenblatt S, Miskin B, Glazer NB, Prince MJ, Robertson KE; Pioglitazone 026 Study Group (2001) The impact of pioglitazone on glycemic control and atherogenic dyslipidemia in patients with type 2 diabetes mellitus. Coron Artery Dis 12: 413-423.

9. Aronoff S, Rosenblatt S, Braithwaite S, Egan JW, Mathisen AL, Schneider RL (2000) Pioglitazone hydrochloride monotherapy improves glycemic control in the treatment of patients with type 2 diabetes: a 6-month randomized placebo-controlled dose-response study. The Pioglitazone 001 Study Group. Diabetes Care 23:1605-1611.

10. Satoh N, Ogawa Y, Usui T, Tagami T, Kono S, Uesugi H, Sugiyama H, Sugawara A, Yamada K, Shimatsu A, Kuzuya H, Nakao K (2003) Antiatherogenic effect of pioglitazone in type 2 diabetic patients irrespective of the responsiveness to its antidiabetic effect. Diabetes Care 26: 2493-2499.

11. Pavo I, Jermendy G, Varkonyi TT, Kerenyi Z, Gyimesi A, Shoustov S, Shestakova M, Herz M, Johns D, Schluchter BJ, Festa A, Tan MH (2003) J Clin Endocrinol Metab 88: 1637-1645.

12. Hanefeld M, Brunetti P, Schernthaner GH, Matthews
DR, Charbonnel BH; QUARTET Study Group (2004) One-year glycemic control with a sulfonylurea plus pioglitazone versus a sulfonylurea plus metformin in patients with type 2 diabetes. Diabetes Care 27: 141-147.

13. Nishio K, Sakurai M, Kusuyama T, Shigemitsu M, Fukui T, Kawamura K, Itoh S, Konno N, Katagiri T (2006) A randomized comparison of pioglitazone to inhibit restenosis after coronary stenting in patients with type 2 diabetes. Diabetes Care 29: 101-206.

14. Hanefeld M (2009) The role of pioglitazone in modifying the atherogenic lipoprotein profile. Diabetes Obes Metab 11: 742-756.

15. Okazaki M, Usui S, Ishigami M, Sakai N, Nakamura T, Matsuzawa Y, Yamashita S (2005) Identification of unique lipoprotein subclasses for visceral obesity by component analysis of cholesterol profile in high-performance liquid chromatography. Arterioscler Thromb Vasc Biol 25: 578-584.

16. Okazaki M, Usui S, Fukui A, Kubota I, Tomoike H (2006) Component analysis of HPLC profiles of unique lipoprotein subclass cholesterols for detection of coronary artery disease. Clin Chem 52: 2049-2053.

17. Adachi T, Ohta H, Yamada H, Futenma A, Kato K, Hirano K (1992) Quantitative analysis of extracellular-superoxide dismutase in serum and urine by ELISA with monoclonal antibody. Clin Chim Acta 212: 89-102.

18. Fujinami A, Obayashi H, Ohta K, Ichimura T, Nishimura M, Matsui H, Kawahara Y, Yamazaki M, Ogata M, Hasegawa G, Nakamura N, Yoshikawa T, Nakano K, Ohta M (2004) Enzyme-linked immunosorbent assay for circulating human resistin: resistin concentrations in normal subjects and patients with type 2 diabetes. Clin Chim Acta 339: 57-63.

19. Fujinami A, Ohta K, Obayashi H, Fukui M, Hasegawa G, Nakamura N, Kozai H, Imai S, Ohta M (2008) Serum brain-derived neurotrophic factor in patients with type 2 diabetes mellitus: Relationship to glucose metabolism and biomarkers of insulin resistance. Clin Biochem 41: 812-817.

20. Tokunaga K, Matsuzawa Y, Ishikawa K, Tarui S (1983) A novel technique for the determination of body fat by computed tomography. Int J Obes 7: 437-445.

21. Deeg MA, Buse JB, Goldberg RB, Kendall DM, Zagar AJ, Jacober SJ, Khan MA, Perez AT, Tan MH; GLAI Study Investigators (2007) Pioglitazone and rosiglitazone have different effects on serum lipoprotein particle concentrations and sizes in patients with type 2 diabetes and dyslipidemia. Diabetes Care 30: 2458-2464.

22. Garvey WT, Kwon S, Zheng D, Shaughnessy S, Wallace P, Hutto A, Pugh K, Jenkins AJ, Klein RL, Liao Y (2003) Effects of insulin resistance and type 2 diabetes on lipoprotein subclass particle size and concentration determined by nuclear magnetic resonance. 
Diabetes 52: 453-462.

23. Adiels M, Borén J, Caslake MJ, Stewart P, Soro A, Westerbacka J, Wennberg B, Olofsson SO, Packard C, Taskinen MR (2005) Overproduction of VLDL1 driven by hyperglycemia is a dominant feature of diabetic dyslipidemia. Arterioscler Thromb Vasc Biol 25: 16971703.

24. Gill JM, Brown JC, Bedford D, Wright DM, Cooney J, Hughes DA, Packard CJ, Caslake MJ (2004) Hepatic production of VLDL1 but not VLDL2 is related to insulin resistance in normoglycaemic middle-aged subjects. Atherosclerosis 176: 49-56.

25. Griffin BA, Packard CJ (1994) Metabolism of VLDL and LDL subclasses. Curr Opin Lipidol 5: 200-206.

26. Packard CJ (2003) Triacylglycerol-rich lipoproteins and the generation of small, dense low-density lipoprotein. Biochem Soc Trans 31(Pt 5): 1066-1069.

27. Adiels M, Taskinen MR, Packard C, Caslake MJ, SoroPaavonen A, Westerbacka J, Vehkavaara S, Häkkinen A, Olofsson SO, Yki-Järvinen H, Borén J (2006) Overproduction of large VLDL particles is driven by increased liver fat content in man. Diabetologia 49: 755-765.
28. Adiels M, Westerbacka J, Soro-Paavonen A, Häkkinen AM, Vehkavaara S, Caslake MJ, Packard C, Olofsson SO, Yki-Järvinen H, Taskinen MR, Borén J (2007) Acute suppression of VLDL1 secretion rate by insulin is associated with hepatic fat content and insulin resistance. Diabetologia 50: 2356-2365.

29. Zhou G, Myers R, Li Y, Chen Y, Shen X, FenykMelody J, Wu M, Ventre J, Doebber T, Fujii N, Musi N, Hirshman MF, Goodyear LJ, Moller DE (2001) Role of AMP-activated protein kinase in mechanism of metformin action. J Clin Invest 108:1167-1174.

30. Saha AK, Avilucea PR, Ye JM, Assifi MM, Kraegen EW, Ruderman NB (2004) Pioglitazone treatment activates AMP-activated protein kinase in rat liver and adipose tissue in vivo. Biochem Biophys Res Commun 314: 580-585.

31. Yamauchi T, Kamon J, Minokoshi Y, Ito Y, Waki H, Uchida S, Yamashita S, Noda M, Kita S, Ueki K, Eto K, Akanuma Y, Froguel P, Foufelle F, Ferre P, Carling D, Kimura S, Nagai R, Kahn BB, Kadowaki T (2007) Adiponectin stimulates glucose utilization and fattyacid oxidation by activating AMP-activated protein kinase. Nat Med 13: 332-339. 